\title{
Late Permian Changes in Conditions of the Atmosphere and Environments Caused by Halogenated Gases
}

\author{
L. Weissflog ${ }^{a}$, N. F. Elansky ${ }^{e}$, K. Kotte ${ }^{b}$, F. Keppler ${ }^{b}$, A. Pfennigsdorff ${ }^{a}$, \\ C. A. Lange ${ }^{a}$, E. Putz ${ }^{d}$, and L. V. Lisitsyna ${ }^{e}$ \\ Presented by Academician G.S. Golitsyn June 27, 2008
}

Received August 1, 2008

DOI: $10.1134 / \mathrm{S} 1028334 \mathrm{X} 09020263$

There are periods in the Earth's history when environmental conditions and the climate sharply changed. Some of such changes were accompanied by mass extinction of living organisms and a decrease in the species diversity. At present, there exist numerous hypotheses and conflicting scenarios of terrestrial and extraterrestrial events which led to such consequences. In particular, the most striking such episode belonging to the Late Permian is related to eruption of volcanoes in Siberia, the impact of a large asteroid, and climatic fluctuations caused by a decrease in the ozone concentration in the atmosphere (see for instance, [1]). By the ratio of isotopes in sedimentary rocks, there was revealed a degradation of vegetation in that period, which was accompanied by an appreciable decrease in productivity of photosynthesis [2]. The photosynthesis reduction resulted in a decrease in $\mathrm{O}_{2}$ and an increase in $\mathrm{CO}_{2}$ concentrations in the atmosphere and oceans. Volcanic emission of $\mathrm{CO}_{2}$ in Siberia in the Late Permian also contributed to a general increase in the $\mathrm{CO}_{2}$ concentration on the Earth. The change in the radiation budget, the warmed-up climate of the Earth, and aridization of some regions on the planet could cause mass extinction of living organisms [1].

\footnotetext{
${ }^{a}$ UFZ-Helmholtz Center for Environmental Research, Leipzig-Halle Ltd., Permoserstrasse 15, Leipzig, D-04318 Germany

${ }^{b}$ Max-Plank-Institute for Chemistry, Heidelberg, 69117 Germany

${ }^{c}$ Northwest University, Potchefstroom Campus, Potchefstroom 2520, South Africa

${ }^{d}$ Institute for Geophysics, Astrophysics, and Meteorology, Karl-Franzens-University Graz, Universitätsplatz 5, A-8010 Graz, Austria

${ }^{e}$ Obukhov Institute of Atmospheric Physics, Russian Academy of Sciences, Pyzhevskii per. 3, Moscow, 119017 Russia
}

The mass extinction of living organisms on the Earth at the boundary between the Permian and Triassic is known to have lasted over a million years (within the interval of $252.3 \pm 0.3-251.4 \pm 0.3 \mathrm{Ma}$ ago), i.e., in a very short period of time in terms of geology. Died out during this period were $90 \%$ of sea species, $60 \%$ of reptile and amphibian families, $30 \%$ of insect varieties, and most terrestrial plants [3]. The gradual and continuous changes in the species diversity of living organisms indicate that the mass extinction was caused by a gradual effect rather than a geologically instantaneous event spanning over several years or centuries. This suggests that such global changes began due to terrestrial causes, and later other, probably, extraterrestrial factors came into play.

This work discusses a new possible cause of changes in the state of the Earth's system and mass extinction of living organisms at the boundary between the Permian and Triassic, which was related to an increased emission of volatile phytotoxicological halogenated hydrocarbons (HHCs) from hypersalt lakes and seas. The possibility for HHC to form actively in water and bottom sediments of such water bodies was revealed in recent years in the course of studying aridization processes during climatic warming $[4,5]$.

\section{NATURAL SOURCES OF HALOGENATED HYDROCARBONS}

We have shown recently that high-volatile HHC, such as chloroform $\left(\mathrm{CHL}, \mathrm{CHCl}_{3}\right)$, trichlorethylene (TRI, $\mathrm{C}_{2} \mathrm{HCl}_{3}$ ), tetrachlorethylene (PER, $\left.\mathrm{C}_{2} \mathrm{Cl}_{4}\right)$, and methylchloroform ( $\mathrm{MC}, \mathrm{C}_{2} \mathrm{H}_{3} \mathrm{Cl}_{3}$ ), key substances for the chemistry of the atmosphere, are formed by vital functions of microorganisms in natural hypersalt chloride lakes of the Caspian region and chloride-salt dry lakes of South Africa $[4,5]$. To assess emission of the above-mentioned HHC from the $5-\mathrm{km}^{2}$ area of a large hypersalt chloride lake located in southeastern Kalmykia, we applied the method described in [5]. 
Table 1. Calculated annual biogenic emission of halogenated hydrocarbons from the salt lake in Kalmykia, Kara Bogaz Gol, and Zechstein paleosea compared to industrial and total (without regard for emission from salt lakes) natural and anthropogenic global emission in 1996 (Mt Cl/yr) [8]

\begin{tabular}{c|c|c|c|c|c}
\hline Substance & $\begin{array}{c}\text { Salt lake } \\
\left(5 \mathrm{~km}^{2}\right)\end{array}$ & $\begin{array}{c}\text { Kara Bogaz Gol } \\
\left(18000 \mathrm{~km}^{2}\right)\end{array}$ & $\begin{array}{c}\text { Zechstein Sea } \\
\left(600000 \mathrm{~km}^{2}\right)\end{array}$ & Current industry & $\begin{array}{c}\text { Current global } \\
\text { emission }\end{array}$ \\
\hline CHL & $9.5 \times 10^{-6}$ & 0.034 & 1.136 & 0.062 & 0.56 \\
TRI & $11.1 \times 10^{-6}$ & 0.040 & 1.343 & 0.195 & 0.22 \\
PER & $10.8 \times 10^{-6}$ & 0.039 & 1.317 & 0.313 & 0.33 \\
MC & $0.55 \times 10^{-6}$ & 0.002 & 0.050 & $0.572 *$ & 0.59 \\
\hline
\end{tabular}

* Prior to validity of the Montreal Protocol (1991) restricting MC production. In 1995, MC production made up $0.234 \mathrm{Mt}$ Cl per year.

Glass test tubes $(20 \mathrm{ml}$ in volume, inner diameter $20 \mathrm{~mm}$ ) were filled with wet reddish mineral-salt bottom deposits of this salt lake $(7.5 \mathrm{~g})$ and $4 \mathrm{M}$-aqueous $\mathrm{NaCl}$ solution $(2.5 \mathrm{ml})$. The area of the phase interface between the $\mathrm{NaCl}$ solution and the air in the glass tube was $3.14 \mathrm{~cm}^{2}$. After keeping closed test tubes for 42 days at the temperature of $25^{\circ} \mathrm{C}$ with alternation of daylight and darkness (12/12 h), the HHC concentration in the air inside the glass test-tube was determined by the method of gas chromatography. The data obtained were used for assessing the HHC annual emission under natural conditions. We have determined that annual emission of CHL, TRI, PER, and MC from the $5-\mathrm{km}^{2}$ surface of this salt lake into the atmosphere makes up 9.5, 11.1, 10.8, and $0.55 \mathrm{t}$ respectively (Table 1 ). Hence, the experiments carried out confirmed conclusions made in [5] that salt lakes represent intensive sources of chemically active HHC.

At present, the Kara Bogaz Gol hypersalt bay occupying an area of $18000 \mathrm{~km}^{2}$ on the eastern coast of the Caspian Sea represents an immense evaporating basin. The bay is one of the saltiest water bodies in the world. As is evident from calculations with the use of data of the "in test-tube" experiment, HHC emission from the Kara Bogaz Gol Bay surface $\left(18000 \mathrm{~km}^{2}\right)$ is to exceed

Table 2. Chemical composition of seawater in the Late Permian, calculated by the Hardie method [6] based on mineralogy of the Stassfurt salt zone $(80.0-81.5 \mathrm{~m})$ formed during evaporation of the Zechstein paleosea. Concentrations of elements (ppm) are reduced to $\mathrm{Na}$ concentrations in presentday seawater

\begin{tabular}{l|c|c|c}
\hline Ion & $\begin{array}{c}\text { Stassfurt salt } \\
\text { zone }\end{array}$ & $\begin{array}{c}\text { Present-day } \\
\text { seawater }\end{array}$ & $\begin{array}{c}\text { Difference, } \\
\%\end{array}$ \\
\hline $\mathrm{Ca}$ & 436 & 411 & +6 \\
$\mathrm{Mg}$ & 1.081 & 1.293 & -16 \\
$\mathrm{Na}$ & 10.762 & 10.762 & 0 \\
$\mathrm{~K}$ & 429 & 399 & +7.5 \\
$\mathrm{Cl}$ & 19.353 & 19.353 & 0 \\
$\mathrm{SO}_{4}$ & 2.011 & 2.709 & -25.8 \\
$\mathrm{HCO}_{3}$ & 120 & 140 & -14.3 \\
\hline
\end{tabular}

by 3000-4000 times the emission of these substances from the surface of the salt lake $\left(5 \mathrm{~km}^{2}\right)$ under study (Table 1). The integral emission of HHC (except for MC) from all the hypersalt lakes on the planet is thus seen to exceed total industrial emissions and be comparable with global emissions from all other sources [8].

Intense emission from the Caspian region is indirectly confirmed by a high (for the whole territory of Russia) trichloroacetic acid (TCA) concentration in local vegetation (30-70 $\mu \mathrm{g}$ per $1 \mathrm{~kg}$ of dry substance that is 20 times greater than the background level). The acid is formed under oxidation of HHC and, mainly, TRI and PER $[4,9,10]$.

In the Late Permian, conditions for HHC biogenic production were the most favorable. In particular, in the region of present-day Europe, the Zechstein inland hypersalt shallow sea was formed, the surface area of which made up about $600000 \mathrm{~km}^{2}$. The sea was located within the latitudinal belt $20^{\circ}-30^{\circ} \mathrm{N}$ in the center of the Pangea continent, approximately where the Sahara is situated at present. Due to the hot and dry continental (arid) climate, water from this shallow sea rapidly evaporated and solar salt $\mathrm{NaCl}$ accumulated there at a rate of up to $10 \mathrm{~cm}$ per year. Such processes are taking place at present as well, for instance, in the Dead and Caspian seas, as well as in the Persian Gulf.

The salt content in seawater in the Late Permian is close to the present-day concentration (Table 2) [6]. The similarity of hydrochemical, hydrological, and climatic conditions corresponding to the Zechstein paleosea in the Permian and the Kara Bogaz Gol Bay in the Holocene suggests that the activity of microorganisms in these periods was also similar. Halophilic archebacteria were found in Permian-Triassic distinct salt deposits [7]. Such archebacteria were also found in present-day salt lakes, for instance, in the Dead Sea and Great Salt Lake, as well as in sedimentary deposits in all the continents. This allows for extrapolating the high-volatile HHC production in present salt lakes to the Permian Zechstein Sea. We obtain that emission of such HHC as CHL, TRI, and PER would have made up $1-2 \mathrm{Mt} / \mathrm{yr}$ (Table 1). This is nearly an order of magnitude greater that emissions of present-day industry. As to MC, its annual emission from the Zechstein Sea is 
comparable with global industrial emissions after restrictions undertaken in 1995 in response to the Montreal Protocol.

The activity of microorganisms in hypersalt lakes varies depending on the season and environment (for instance, temperature, solar radiation, humidity, and nutrients). We assessed biogenic emission for some average conditions. Under favorable conditions, emission is substantially higher. Permian giant salt deposits comparable in abundance to deposits in the Zechstein Sea occur amidst other deposits in present-day South and North America (for instance, in the Delaware basin of an area of $\sim 26000 \mathrm{~km}^{2}$ ) and other regions. It is likely that HHC emission was nearly the same amount there as in the Zechstein Sea.

When suggested that the volatile HHC lifetime in the atmosphere in the Late Permian nearly corresponded to current values, the HHC average concentration in surface air would thus be expected to make up about 200, 20, 130, and 1500 billions $^{-1}$ for CHL, TRI, PER, and MC respectively. Nearly the same high concentrations of HHC were observed in the late 1990s in some industrial regions of Central Europe. It is there that the highest (up to $270 \mu \mathrm{g} / \mathrm{kg}$ ) concentration of toxic trichloroacetic acid (TCA) in plants was established that resulted in degradation and extinction of forest massifs [9]. It is apparent that high concentrations of HHC - predecessors of TCA-promoted formation and accumulation of this hazardous toxic substance in plants in the center of the Pangea continent as well. The condition necessary for TCA generation-the presence of salt aerosols in the air, which assisted in transformation of neutral halogenated compounds into active forms through heterogeneous interactions-was probably met [5].

High-volatile HHC also including highly toxic compounds, such as dioxins and furans, were emitted into the atmosphere not only from hypersalt lakes. Hightemperature chemical reactions running at chlorinated coal combustion in volcanic processes, reactions between chlorides of salt deposits and organic carbon, which was formed during biomass combustion, and emission from coal and petroliferous strata could be additional sources of HHC [9].

At present, the contribution of all these sources into the global budget of high-volatile HHC is not so large as, in particular, is seen from Table 1 . The only exception is chloroform, most of which is emitted from the ocean and soil. It is likely that the relationship between natural sources in the Late Permian was nearly the same, and the contribution of biogenic emissions from saltwater bodies dominated over all other kinds.

\section{THE IMPACT OF HALOGENATED HYDROCARBONS ON THE ATMOSPHERE, VEGETATION, AND CLIMATE}

Some HHCs formed in hypersalt lakes are phytotoxicological (for instance, CHL, TRI, PER, MC) and decompose in the atmosphere and plant cells into substances exhibiting still more expressed phytotoxicological properties: tri-, dichloroacetic acid, and phosgene [9]. The impact of $\mathrm{HHC}$ and products of their oxidation on different plants are discussed in $[10,11]$. It is pointed out in the works that a greater photooxidation stress under arid conditions, which is caused by water deficiency, could lead to an increase in the generation rate for TCA and, finally, $\mathrm{HCl}$ [9]. In semideserts and deserts, HHCs exhibit the highest phytotoxicological potential and heavily affect the vegetation. Information has recently been published about a $30 \%$ decrease in plant viability and a sharp increase in moisture evaporation by damaged plants, a decreasing biomass generation and stress endurance due to HHC impact, soil salinity, and higher ultraviolet radiation $[11,12]$. As shown in [11], the processes are one of the main causes of current desertification in South Africa and Central Asia.

It may be suggested that the phytotoxicological effect of $\mathrm{HHC}$ on plants comprising chlorophyll also showed up in the Late Permian with its hot and arid climate not only near such a source as the Zechstein Sea but at a great distance from it as well (up to several thousands of kilometers) because of the distant transfer of gas admixtures and aerosol.

After entering the atmosphere, highly volatile HHCs may reach the stratosphere, where they initiate photochemical processes causing destruction of the ozone layer. MC represents the most active ozonedestroying compound since it has the longest lifetime (4.8 years) and a considerable part of it (about 10\%) reaches the stratosphere. Due to a shorter lifetime, only $0.4 \%$ of CHL emitted into the atmosphere is transferred into the upper atmosphere. Still smaller values are characteristic of TRI and PER as the most short-lived compounds.

An increased emission of HHCs, especially MC and CHL, in the Late Permian resulted in substantially greater flow to the stratosphere compared to the present time. It seems plausible as well that the hot and arid climate of the Pangea huge continent promoted a more active convective transfer of $\mathrm{HHC}$ into upper layers of the atmosphere. The position of main HHC sources coinciding with the subtropical high-altitude frontal zone $\left(\sim 30^{\circ} \mathrm{N}\right)$, i.e., a tropopause gap, through which the air exchange does proceed between the troposphere and stratosphere, could impart additional acceleration to the vertical transfer. Under such conditions, shortlived HHCs could have also made a substantial contribution to destruction of the ozone layer in the Late Permian. 
Evidence of a sharp increase in ultraviolet radiation flow on the green surface during mass extinction of living organisms is presented in [13]. The explanation suggested by some authors about ozone layer destruction under the effect of hydrogen sulfide, an increased emission of which was caused by retardation of exchange processes in the ocean, was not confirmed by modeling carried out recently [14]. In our opinion, partial destruction of the ozone layer $250 \mathrm{Ma}$ ago could be of the same nature as that in the early 1990s when an increased concentration of halogenated compounds was registered in the stratosphere. The compounds were assumed to be of anthropogenic origin, but as revealed nowadays, part of them could have been caused by the life activity of halophilic bacteria in water and bottom deposits of salt lakes and seas. A corresponding increase in short-wave ultraviolet radiation in the Permian, which is described in [13], caused severe damage to the Permian biosphere. In addition to the direct effect of HHC on plants, the exhaustion of the stratospheric ozone layer and an increase in the ultraviolet radiation level should be assessed as a secondary impact of these factors on vegetation.

Aerobic living organisms are exposed to abiotic stresses such as drought, heat, salinity, ultraviolet radiation, and high concentrations of $\mathrm{SiO}_{2}$ and other chemically active gases in the air. Such factors may increase phytotoxicity. In particular, a great amount of $\mathrm{SO}_{2}$ and $\mathrm{HCl}$ was emitted into the atmosphere due to giant volcanic activity on the territory of present-day Siberia in the Late Permian. Chloride-sulfate aerosols rising as immense masses from the Zechstein dried hypersalt sea, its lagoons, and waterlogged grounds could increase HCC phytotoxicity. Long-range aerosol transmission could have led to soil salinity on a vast territory of the Pangea continent. Among other factors, the consumption of salt by vegetation is known to result in an osmotic potential shift that, in turn, causes water loss by a plant, as well as nutrient deficiency. This scenario is also probable for the Late Permian.

Active under these conditions is the system of direct coupling and feedback: an increased concentration of HHC in the atmosphere causes vegetation failure and degradation that results in soil dehydration, salinity, desertification, and an increase in the concentration of greenhouse gases, $\mathrm{H}_{2} \mathrm{O}$, and $\mathrm{CO}_{2}$ in the air. Moreover, HHCs destroy the ozone layer, which is accompanied by an increase in the ultraviolet radiation level. These combined effects lead to increasing salinity of the surface water and, hence, a further growth in HHC emission. Thus, the drought effect on living organisms initially determined only by climatic conditions in the Late Permian is sharply enhanced. Finally, these phenomena would have resulted in substantial activation of plants and living organisms extinction. Most likely, halogenated hydrocarbons in the atmosphere are, to be sure, not the only cause of the mass extinction but could initiate the process due to long-term continuous emission from hypersalt lakes and vast salt deposits.

Generation of the Pangea huge continent, the change in the climate, atmosphere, and vegetation substantially affected sea ecosystems as well. Water mixing worsened because of violation of oceanic circulation. Surface waters were enriched with methane and hydrogen sulfide [14]. Simultaneously, a great amount of humic and fulvic acids dissolved in water was derived from the continent. Water coloring resulted in an increase in light absorption and a decrease in phytoplankton photosynthesis. To compensate for the decrease, phytoplankton rose to upper layers of the water where it was exposed to the negative effect of increased ultraviolet radiation. The unfavorable radiation regime, increased hydrogen sulfide concentration, and decreased oxygen content in the upper layers of water reduced the amount of phytoplankton and violated the trophic chain. As a result, sea organisms would have died and their species diversity would have been reduced.

Evidently, such processes showed up differently in the Late Permian on the territory of the Earth. As a consequence, there exist great differences in the mass extinction of terrestrial and sea organisms from region to region. The geological, climatic, and natural changes that took place at that time are covered in detail in the scientific literature. We have demonstrated only that volatile HHCs of biogenic origin could have played a great part (and, probably, initiating) in these changes.

\section{COMPARISON AND PROSPECTS}

Climatic and paleotoxicological processes, which were responsible for mass extinction about $250 \mathrm{Ma}$ ago, may also play a crucial role in the recent (sixth) largescale decrease in biodiversity caused by human activity. The rate with which the current mass extinction comes into play is 1000 times greater than that in the preindustrial epoch [15]. A global rise in the temperature and more frequent droughts are leading to progressing desertification and expansion (by the number and surface area) of hypersalt lakes, salt bays, and saline bogs. Moreover, a sea level rise will cause extension of old and formation of new salt ecosystems as the result of flooding of coastal territories and lowlands. In particular, this will lead to increasing emission of natural phytotoxicological HHCs in regions with semiarid and arid climatic conditions. A great amount of salt aerosol will be carried-over by winds from the surface of these dried hypersalt ecosystems. At present, this can be illustrated by the example of Central Asia where several hundreds of thousands of tons of salt aerosol are removed from the former bottom of the Aral dried sea, Kara Bogaz Gol, and saline waterlogged lands of the Caspian Sea coast and transferred over several thousand kilometers every year. In combination with the high temperature, intense solar radiation, and the increasing contribution of anthropogenic admixtures, the area of arid zones in 
Central Asia is progressively growing. In this case, it is well to bear in mind that present-day observations cover the interval spanning several decades only. On the other hand, processes relating to the Late Permian span the range of one million years. In this regard, modern attainments do not yet allow definite conclusions as to what extent the present-day natural and anthropogenic HHC emissions in combination with increasing stress because of water deficiency may provoke or facilitate the mass extinction of living organisms on the Earth.

\section{ACKNOWLEDGMENTS}

We are grateful to Professor S. Bower (Karl-Franzens-University, Graz, Austria) for effective discussions and Professor A.S. Alekseev for helpful remarks.

This work was supported in part by the European Commission, EU projects ECCA (IC 15CT96-0106) and TRIDES (ICA2-CT-2000-10038); the Ministry of Education and Research, Germany; the National Foundation for Research, Republic of South Africa, STC project HALOTOX, 39.6.F1A.1.A; the Russian Foundation for Basic Research, project nos. 07-05-00428, 07-05-12063; and the International Scientific and Technical Center, project nos. 2770 and 2773.

\section{REFERENCES}

1. J. T. Kiehl and Ch. A. Shields, Geology 33, 757 (2005).
2. M. J. de Wit, J. G. Gosh, S. de Villiers, et al., J. Geol. 110, 227 (2002).

3. D. H. Erwin, How Life on Earth Nearly Ended 250 Million Years Ago (Princeton Univ. Press, Princeton, 2006).

4. L. Weissflog, N. Elansky, E. Putz, et al., Atmos. Environ. 38, 4197 (2004).

5. L. Weissflog, S. de Lange, A. Pfennigsdorff, et al., Geophys. Res. Lett. 32 (2005). L01401, doi: 1029/2004GL020807.

6. L. A. Hardie, Annu. Rev. Earth and Planet. Sci. 19, 131 (1991).

7. T. J. McGenity, R. T. Gemmell, W. D. Grant, et al., Environ. Microbiol. 2, 243 (2000).

8. W. C. Keene, R. T. Khalil, D. J. Erikson, et al., J. Geophys. Res. 104, 8429 (1999).

9. L. Weissflog, A. Pfennigsdorff, G. Martinez-Pastur, et al., Atmos. Environ. 35, 4511 (2001).

10. L. Weissflog, G. Krueger, N. Elansky, et al., Chemosphere 65, 975 (2006).

11. C. A. Lange, L. Weissflog, R. J. Strasser, et al., South Afr. J. Bot. 70, 683 (2004).

12. A. J. Strauss, G. H. J. Krüger, P. D. R. van Herden, et al., South Afr. J. Bot. 70, 751 (2004).

13. H. Vissher, C. V. Looy, M. E. Collinson, et al., Proc. Nat. Acad. Sci. USA 101, 12952 (2004).

14. J.-F. Lamarque, M. E. Kiehl, and J. J. Orlando, Geophys. Res. Lett. 34, L02801 (2007), doi: 10.1029/2006 GL028384.

15. A. Djoghlaf, Global Biodiversity Outlook 2 (UNO-Secretariat of the Convention on Biological Diversity, Montreal, 2006). 